\title{
RISCOS FíSICO, QUÍMICO E BIOLÓGICO EM PORTUÁRIOS E POTENCIALIDADES PARA ALTERAÇÕES RESPIRATÓRIAS*
}

\author{
Tatiele Roehrs Gelati ${ }^{1}$, Clarice Alves Bonow ${ }^{2}$, Andréia Martins do Couto ${ }^{1}$, Marlise Capa Verde de Almeida ${ }^{3}$, \\ Daniela Inês Thier Roloff', Marta Regina Cezar-Vaz ${ }^{4}$
}

\begin{abstract}
RESUMO: Objetivou-se identificar as fontes de exposição dos trabalhadores portuários avulsos aos riscos químico, físico e biológico no ambiente laboral, com potenciais para alterações da função respiratória. Estudo de caráter quantitativo, exploratório, com técnica observacional não-participante e direta de trabalhadores de um porto naval do sul brasileiro. A coleta de dados ocorreu de julho a dezembro de 2014, sendo realizadas 87 observações de 66 trabalhadores. Realizou-se análise descritiva dos dados, por meio de frequência absoluta e percentual. As fontes predominantes de exposição ao risco físico foram frio, umidade e radiação não ionizante. As fontes de exposição ao risco químico decorreram da movimentação de grãos, fertilizantes e gases combustíveis, e o risco biológico observado foi a presença de pombos. O trabalhador portuário está exposto a fontes de riscos ocupacionais à saúde respiratória que variam conforme as cargas, atividades laborais e locais de trabalho.
\end{abstract}

DESCRITORES: Risco ocupacional; Doenças respiratórias; Saúde do trabalhador; Enfermagem; Riscos Ambientais.

\section{PHYSICAL, CHEMICAL AND BIOLOGICAL HAZARDS TO PORT WORKERS AND THEIR POTENTIAL TO CAUSE RESPIRATORY DISORDERS}

ABSTRACT: The present study aimed to identify the sources of chemical, physical and biological hazards to which temporary port workers are exposed in the work environment, which may cause respiratory disorders. Quantitative and exploratory study with direct nonparticipant observation of workers from a maritime port in Southern Brazil. Data was collected from July to December 2014, and 87 observations of 66 workers were made. Descriptive statistics was performed with absolute and relative frequencies (percentage). The predominant sources of physical hazards were cold, moisture and non-ionizing radiation. The sources of chemical hazard were associated with the handling of grains, fertilizers and combustible gases, and the biological hazard observed was the presence of pigeons. Port workers are exposed to occupational hazards that pose respiratory health risks, depending on the type of cargo, activities and workplace.

DESCRIPTORS: Occupational risks; Respiratory diseases; Occupational health; Nursing; Environmental Risks.

\section{RIESGOS FÍSICO, QUÍMICO Y BIOLÓGICO EN PORTUARIOS; Y POTENCIALIDADES DE ALTERACIONES RESPIRATORIAS}

RESUMEN: Se objetivó identificar las fuentes de exposición de trabajadores portuarios expuestos a riesgos químico, físico y biológico en su ámbito laboral, con potenciales de alteración de la función respiratoria. Estudio cuantitativo, exploratorio, aplicando técnica observacional no participante y directa de trabajadores de un puerto naval del sur brasileño. Datos recolectados de julio a diciembre de 2014, habiendo sido realizadas 87 observaciones de 66 trabajadores. Se realizó análisis descriptivo de los datos, mediante frecuencia absoluta y porcentual. Las fuentes predominantes de exposición al riesgo físico fueron: frío, humedad y radiación no ionizante. Las fuentes de exposición al riesgo químico derivaron del traslado de granos, fertilizantes y gases combustibles; y el riesgo biológico observado fue la presencia de palomas. El trabajador portuario está expuesto a fuentes de riesgos laborales para su salud respiratoria, los cuales varían en función de las cargas, actividades laborales y lugares de trabajo.

DESCRIPTORES: Riesgos Laborales; Enfermedades Respiratorias; Salud Laboral; Enfermería; Riesgos Ambientales.

*Artigo extraído da dissertação intitulada "Alterações da função respiratória em trabalhadores portuários e a exposição a fontes de riscos ocupacionais". Universidade Federal do Rio Grande, 2015.

${ }^{1}$ Enfermeira. Doutoranda em Enfermagem. Universidade Federal do Rio Grande. Rio Grande, RS, Brasil.

${ }^{2}$ Enfermeira. Doutora em Enfermagem. Docente da Universidade Federal de Pelotas. Pelotas, RS, Brasil.

${ }^{3}$ Enfermeira. Doutora em Enfermagem. Técnica do Laboratório de Práticas em Enfermagem da Universidade Federal do Rio Grande. Rio Grande, RS, Brasil.

${ }^{4}$ Enfermeira. Doutora em Filosofia da Enfermagem. Docente de Enfermagem da Universidade Federal do Rio Grande. Rio Grande, RS, Brasil 


\section{- INTRODUÇÃO}

Os agravos ao sistema respiratório podem estar relacionados a diversas fontes de exposição presente no ambiente de trabalho, bem como à condição orgânica e ao tabagismo ${ }^{(1)}$. As principais fontes exposição atmosféricas advém de indústrias e veículos automotores ${ }^{(2)}$, sendo essa uma condição socioambiental que provoca impactos negativos às condições de saúde do trabalhador.

A identificação de tais condições é ação primordial para que o enfermeiro possa reconhecer e avaliar as carcaterísticas ocupacionais que podem estar ou vir a influenciar positiva ou negativamente no processo saúde-doença de diferentes trabalhadores. Além disso, identificar as fontes de exposição que interferem no sistema orgânico do trabalhador, a fim de planejar intervenções para evitar e/ou minimizar agravos à saúde.

Dentre o conjunto dos riscos referidos, citam-se os riscos físicos, como o vento, a chuva, a umidade e a radiação não ionizante; os riscos químicos, como a formação de poeira e gases combustíveis; e o biológico, como os vírus e bactérias. Decorrem da própria característica de diversos ambientes de trabalho, salientando nesse estudo, o trabalho portuário. Este destaca-se pela importância para a economia no país, tendo movimentado mais de 320,9 milhões de toneladas de mercadorias só no primeiro semestre de $2016^{(3)}$. O Brasil se comporta, assim, como uma importante potência na indústria portuária.

O trabalho portuário é desenvolvido por trabalhadores com vínculo empregatício ou por trabalhadores portuários avulsos (TPA), sendo este último referido, de intermediação do Órgão Gestor de Mão-de-obra (OGMO) do respectivo porto ou do sindicato da categoria ${ }^{(4)}$, e foco do presente estudo. Pesquisas realizadas no Brasil $^{(5-6)}$ e no mundo ${ }^{(7-8)}$ destacam o impacto das condições socioambientais do trabalho na sáude de trabalhadores portuários, que se encontram expostos a diferentes fontes de riscos ambientais, com potencial ao desenvolvimento de agravos e doenças.

Nessa realidade ocupacional, o enfermeiro, por meio de seu conhecimento clínico, em cooperação com os Serviço Especializado em Segurança e Saúde do Trabalho Portuário (SESSTP), precisam reconhecer os riscos, bem como desenvolver estratégias à interrupção ou minimização destes. $O$ SESSTP está previsto na Norma Regulamentadora 29- Segurança e Saúde no Trabalho Portuário (NR29), e tem como responsabilidade realizar a identificação das condições de segurança nas operações portuárias afim de detectar os agentes de riscos existentes de forma a eliminar ou neutralizar estes ${ }^{(9)}$.

O trabalho portuário brasileiro é desenvolvido por seis diferentes categorias de trabalho: a capatazia, os consertadores de carga e os trabalhadores em bloco, que realizam atividade em terra firme; a estiva e os conferentes de carga, que realizam atividade a bordo do navio; e os vigias de embarcações, que realizam atividade em ambos os ambientes. O trabalho pode ainda ser desenvolvido no ambiente interno e externo(4).

Referente ao trabalho a bordo, ele é realizado no porão em que são armazenadas as cargas transportadas e nos pavimentos internos dos navios. Já o trabalho em terra firme é desenvolvido nos armazéns e na oficina, esta última em atividades de soldagem. No ambiente externo e em terra firme, o trabalho é desenvolvido no cais, local de atracação de embarcações e carregamento de cargas, assim como no pátio automotivo, com a execução de atividades de peação e despeação de veículos nos caminhões cegonha a serem transportados ${ }^{(4)}$.

A bordo das embarcações e no ambiente externo, o trabalho é desempenhado no convés, podendo citar os sinalizadores que realizam a comunicação com os operadores de guincho e guindaste e nas rampas de acesso às embarcações. Este ficam expostos à poeira proveniente do carregamento de cargas a granel e aos gases da queima de combustíveis, oriundo da movimentação portuária e da movimentação de automóveis e máquinas ${ }^{(4)}$.

Conforme estudo realizado pela Occupational Safety and Health Administration (OSHA), os trabalhadores portuários, operadores de equipamentos pesados e motoristas de caminhões, estão expostos ao material particulado do diesel, que inclui fuligem constituída principalmente de carbono, sulfatos e silicatos. Estes a curto prazo podem causar sintomas como dor de cabeça, irritação nos olhos e garganta. Devido ao tempo prolongado de exposição, pode aumentar o risco de doenças 
cardiovasculates, cardiopulmonares e respiratórias ${ }^{(10)}$.

Nesse ambiente de trabalho, o principal fertilizante movimentado no porto estudado foi a Ureia (NH3), composto nitrogenado que, quando inalado, pode ser irritante ao sistema respiratório, causando tosse e espirro ${ }^{(11)}$. Os sintomas podem ser potencializados quando o trabalhador também está exposto a gases tóxicos, tornando agravante e prejudicial à saúde respiratória ${ }^{(12)}$.

Salienta-se ainda que os TPA estão expostos a gases como o óxido de nitrogênio. Este, ao entrar em contato com o epitélio respiratório, estimula a formação de radicais livres de oxigênio e de nitrogênio, induzindo o estresse oxidativo, mecanismo que provoca inflamação local e sistêmica nas vias aéreas, podendo causar Doença Pulmonar Obstrutiva Crônica (DPOC) ${ }^{(10,12)}$.

Configura-se, assim, a relevância desse estudo, para o enfermeiro identificar as possíveis alterações clínicas e agravos à saúde decorrente do ambiente do trabalho do TPA, de modo a fortalecer suas ações frente à assistência à saúde respiratória. Destaca-se neste estudo, conforme a NR-29, o SESSTP possui em seu quadro de dimensiomanto mínimo Enfermeiro do Trabalho, pois é empresa com mais de 751 trabalhadores.

Neste contexto, tem-se como objetivo identificar fontes de exposição dos TPA aos riscos químico, físico e biológico no ambiente laboral, com potencial para alterações da função respiratória.

\section{- MÉTODO}

Estudo quantitativo, observacional, descritivo, desenvolvido em um porto naval do sul brasileiro. O local do estudo foi o Porto Novo, área do Porto Organizado, onde se encontram as áreas do cais público e área de roll-on/roll-off (tipo de navio que é destinado a cargas diversas) de construção e reparo naval. Possui $1.952 \mathrm{~m}$ de cais acostável, uma área operacional interna de aproximadamente $60.000 \mathrm{~m}^{2}$, compreendida por 20 armazéns para estocar mercadorias. As cargas transportadas são desde celulose, pás eólicas até a granéis sólidos, como soja, trigo, e produtos químicos, como os fertilizantes ${ }^{(4)}$.

A coleta dos dados foi realizada por meio da técnica de observação não participante dos trabal hadores portuários avulsos, no exercício de seu trabalho, com foco nas fontes de riscos ocupacionais físico, químico e biológico, com potenciais para desenvolver alterações na função respiratória destes trabalhadores.

A observação foi orientada por um instrumento tipo checklist, construído a partir das características do ambiente portuário. Este constituiu-se de informações da caracterização do trabalhador, bem como questões fechadas referente aos instrumentos de trabalho utilizados, as fontes de riscos biológico, químico e físico e tipos de cargas transportadas. Houve aporte das Normas Regulamentadoras (NR), mais especificamente as NR-29 e NR-15, relativas a Segurança e Saúde no Trabalho Portuário e Atividades e Operações Insalubres, respectivamente, que são regidas pela Consolidação das Leis do Trabalho (CLT), do Ministério do Trabalho e Emprego ${ }^{(9,13)}$.

A observação foi realizada de forma direta, sem participação e/ou influência nas atividades dos TPA, por integrantes do grupo de pesquisa Laboratório de Estudo e Processos Socioambientais e Produção Coletiva de Saúde. Foram realizadas por duas observadoras (em duplas) para o mesmo trabalhador, a fim de fortalecer os detalhes deste em atividade, permitindo maior fidedignidade e rigor na coleta dos dados.

O direcionamento e o foco da observação foram delineados pelas observadoras, de forma a comporem a diversidade dos ambientes e de atividades de trabalho. Ocorreram durante dias da semana, nos turnos manhã e tarde (durante a noite não foi possível, pois não havia equipe de Segurança do Trabalho para acompanhamento), no período de julho a dezembro de 2014, com média de 8 a 9 horas diárias.

Foram realizadas 87 observações de 66 TPA. Um mesmo trabalhador poderia ter sido observado em diferentes momentos e atividades, ou seja, a repetição dos trabalhadores decorreu da característica própria do trabalho portuário, uma vez que uma mesma categoria de trabalho pode desenvolver diversas atividades em diferentes ambientes. Todos os trabalhadores atenderam os critérios de 
inclusão, ou seja, estar em exercício de suas atividades para que fossem observados.

As categorias observadas foram a capatazia (atividade de movimentação de mercadorias, tais como recebimento, conferência, transporte interno, abertura de volumes para conferência em Aduana, organização de carregamento e descarga de embarcações e outras), a estiva (responsável pela colocação, retirada e arrumação de cargas nos porões e convés de embarcações) e conferência de carga (atividade de contagem de volumes, anotações de características, procedência ou destino de cargas, verificação do estado das mercadorias e outras ações nas operações de carregamento e descarga de embarcações). Todas são atividades externas no cais.

Demais categorias de trabalhadores, no momento da observação, não realizavam atividade ou não foi possível o acesso no ambiente de trabalho. As variáveis observadas foram as fontes de riscos químico, físico e biológico, as cargas manuseadas pelos trabalhadores e o local onde ocorreu o trabalho.

A análise dos dados foi realizada por meio de descrição das médias e frequências das variáveis investigadas com auxílio do software Statistical Package for Social Sciences (SPSS), versão 21.0. As normas éticas de pesquisa em seres humanos foram respeitadas, conforme as recomendações da Resolução do Conselho Nacional de Saúde n 466 de 12 de dezembro de 2012(14). O projeto foi aprovado em 16 de julho de 2013 pelo Comitê de Ética em Pesquisa na área da Saúde da Universidade Federal do Rio Grande, sob o n 118/2013.

\section{RESULTADOS}

Foram realizadas 87 observações com uma amostra de conveniência de 66 TPA, todos do sexo masculino. As observações foram realizadas durante todo o período em que os trabalhadores estavam desenvolvendo suas atividades, o que pode representar uma ou mais observações por turno de trabalho. O critério estabelecido foi observar pelo menos uma vez as diferentes atividades e categorias de trabalho. Destaca-se que a categoria da capatazia predominou nas observações por ser a maior em número de trabalhadores e desenvolver seu trabalho principalmente no cais, local em que, majoritariamente, é desempenhado o trabalho portuário.

A média de idade foi de 51,7 anos (desvio padrão - DP $\pm 8,36$ ), com mínimo de 37 anos e máximo de 73 anos. O tempo de trabalho médio foi de 15,35 anos ( $\mathrm{DP} \pm 1,85$ ), com mínimo de 5 anos e máximo de 17 anos. Referente à cor da pele, a maioria considerou-se de cor branca ( $n=49 ; 74,7 \%)$ e, quanto ao estado civil, ( $n=37 ; 56 \%$ ) eram casados. Demais dados de caracterização estão apresentados na Tabela 1. 
Tabela 1 - Locais e atividades observadas do ambiente de trabalho portuário. Porto naval do sul brasileiro, RS, Brasil, 2014

\begin{tabular}{|c|c|c|c|c|}
\hline $\begin{array}{l}\text { Categorias } \\
\text { profissionais } \\
\text { observadas }\end{array}$ & $\begin{array}{l}\text { Locais observados } \\
\mathbf{n = 8 7}\end{array}$ & Atividades observadas & $\mathbf{n}$ & $\%$ \\
\hline \multirow[t]{15}{*}{ Capatazia } & \multirow[t]{9}{*}{ Cais $(n=66)$} & $\begin{array}{l}\text { Operação de tremonha (funil para recebimento de } \\
\text { carga de grãos) }\end{array}$ & 42 & 48 \\
\hline & & Pedreiro & 5 & 5,7 \\
\hline & & Operação de balança de pesagem & 4 & 4,5 \\
\hline & & Atracação e desatracação de embarcações & 3 & 3,4 \\
\hline & & Ova e desova (carga e descarga de contêiner) & 3 & 3,4 \\
\hline & & $\begin{array}{l}\text { Descarregamento de chata ou avarenga (transporte } \\
\text { de mercadoria para embarcação não atracada no cais) }\end{array}$ & 3 & 3,4 \\
\hline & & Operação de retro e pá carregadeira & 2 & 2,2 \\
\hline & & Operação de guindaste & 2 & 2,2 \\
\hline & & $\begin{array}{l}\text { Calceteiro (atividade de reparo no cais com uso de } \\
\text { marretas e pás de pedreiro) }\end{array}$ & 2 & 2,2 \\
\hline & \multirow{2}{*}{$\begin{array}{l}\text { Pátio automotivo } \\
(\mathrm{n}=4)\end{array}$} & Amarração e desamarração de cargas & 3 & 3,4 \\
\hline & & Motorista subidor & 1 & 1,1 \\
\hline & \multirow[t]{2}{*}{ Oficina $(n=3)$} & Marcenaria & 2 & 2,2 \\
\hline & & Soldagem & 1 & 1,1 \\
\hline & \multirow{2}{*}{$\begin{array}{l}\text { Portão de entrada } \\
(\mathrm{n}=4)\end{array}$} & Conferência dos caminhões & 3 & 3,4 \\
\hline & & $\begin{array}{l}\text { Auxílio no carregamento e descarregamento de } \\
\text { mercadorias }\end{array}$ & 1 & 1,1 \\
\hline \multirow[t]{3}{*}{ Estiva } & $\begin{array}{l}\text { Convés do navio } \\
(\mathrm{n}=2)\end{array}$ & Operação de guincho e sinalização & 2 & 2,2 \\
\hline & $\begin{array}{l}\text { Chata ou avarenga } \\
(\mathrm{n}=2)\end{array}$ & Carregamento de chata ou avarenga & 2 & 2,2 \\
\hline & Porão do navio $(n=3)$ & Limpeza e operação de pá carregadeira & 3 & 3,4 \\
\hline $\begin{array}{l}\text { Conferentes } \\
\text { de carga }\end{array}$ & $\begin{array}{l}\text { Rampa de acesso ao } \\
\text { navio }(n=3)\end{array}$ & Contagem e conferência de volume & 3 & 4,4 \\
\hline
\end{tabular}

Os períodos de observação somaram 167 horas e 10 minutos, sendo realizadas 87 observações, das quais $77(88,5 \%)$ em capatazia, sete $(8,04 \%)$ da estiva e três $(3,4 \%)$ de conferentes de cargas. Nas observações realizadas, a atividade que sobressaiu foi a operação da tremonha $(42 ; 48,2 \%)$, pois a movimentação de cargas a granel é importante segmento de trabalho portuário, seguida da atividade de pedreiro (cinco; 5,7\%) e da operação de balança de pesagem (quatro; 4,5\%).

A quantidade de observações foram sendo acumuladas em função dos turnos de trabalho (manhã e tarde), da diversidade de atividades e categorias nos locais de desenvolvimento do trabalho. Em outras palavras, à medida em que o trabalhador havia concluído a atividade, iniciava-se a observação de outro participante, podendo esse estar no mesmo local físico (mas desempenhando outra função) ou em outro ambiente. Por exemplo, trabalhadores da capatazia que desenvolviam atividade no cais, outros trabalhadores da mesma categoria estavam na marcenaria, fato estabelecido pela própria estrutura organizacional do trabalho.

\section{Fontes de exposição aos riscos ocupacionais físico, químico e biológico}

Foi evidenciada em todas as observações a exposição às fontes produtoras de riscos físico, químico e biológico, potenciais para desenvolver agravos na função respiratória, descritas abaixo (Tabela 2). 
Tabela 2 - Identificação das fontes de riscos ocupacionais físico, químico e biológico observados no ambiente de trabalho portuário. Porto naval do sul brasileiro, RS, Brasil, 2014

\begin{tabular}{lc} 
Fontes de riscos ocupacionais & $\begin{array}{c}\mathbf{n = 8 7} \text { observações } \\
\mathbf{n}(\%)\end{array}$ \\
\hline Físico & $67(77)$ \\
\hline Frio & $63(72,4)$ \\
\hline Vento & $41(47,1)$ \\
\hline Umidade & $22(25,2)$ \\
\hline Radiação não ionizante & $8(9,2)$ \\
\hline Calor & $4(4,6)$ \\
\hline Chuva & $2(2,3)$ \\
\hline Neblina & \\
\hline Químico & $80(91,9)$ \\
\hline Poeira decorrente da movimentação de cargas & $20(23)$ \\
\hline Gases & \\
\hline Biológico & $19(21,8)$
\end{tabular}

Nas observações realizadas, destacam-se as cargas transportadas divididas em fertilizantes, sementes e grãos. Do total das 87 observações referentes a movimentação de fertilizantes, obteve-se predominância da ureia $(\mathrm{NH} 3)$ em $19(21,8 \%)$ observações. A rocha potássica e o fosfato diamônico estiveram presentes em seis $(6,8 \%)$ observações cada; a amônia granulada em quatro $(4,6 \%)$ e o fosfato monoamônico e o cloreto de potássio em três (3,4\%). Dentre os cereais transportados, houve predominância do trigo e do farelo de milho, em cinco $(5,7 \%)$ observações para cada, e a soja em duas $(2,3 \%)$ observações.

Acrescenta-se a presença da poeira atmosférica constituída de material particulado em suspensão, advindo das fumaças e dos materiais sólidos e líquidos do ar. As principais fontes de emissão de gases tóxicos foram os veículos automotores e a ressuspensão de poeira do solo. Houve associação entre a emissão de gases decorrente da circulação de veículos, a movimentação das cargas e a presença de poeira química, bem como o vento, a umidade, a radiação não ionizante e o calor.

\section{Categorias e locais de trabalho - exposição a fontes de riscos}

Com relação aos locais de trabalho observados, trabalhadores que estavam em atividade no cais ( $n=66 ; 75,8 \%$ ). Em todos os locais de trabalho visualizou-se a exposição a riscos físicos, especialmente pelas condições climáticas, com excessão do trabalho em oficina, pois, por ser um ambiente fechado, esta exposição não foi identificada pelos observadores. Já a fonte de risco químico observada decorreu da formação de poeira, por movimentação de cargas. O risco biológico foi observado predominantemente no cais $(66 ; 75,8 \%)$, local que concentrava maior volume de pombos, devido à quantidade de grãos de cereais no solo.

Destaca-se também, entre os dados da observação, que os três tipos de riscos investigados foram visualizados em todos os locais de trabalho, conforme Tabela 3 abaixo. 
Tabela 3 - Local do trabalho portuário e a exposição às fontes de risco físico, químico e biológico conforme as categorias profissionais observadas. Porto naval do sul brasileiro, RS, Brasil, 2014

\begin{tabular}{|c|c|c|c|c|c|}
\hline \multirow{2}{*}{$\begin{array}{l}\text { Categorias } \\
\text { observadas }\end{array}$} & \multirow{2}{*}{$\begin{array}{l}\text { Local de } \\
\text { trabalho }\end{array}$} & \multirow{2}{*}{$\begin{array}{l}n=87 \\
n(\%)\end{array}$} & \multicolumn{3}{|c|}{ Principais fontes de riscos } \\
\hline & & & Químico & Físico & Biológico \\
\hline \multirow[t]{4}{*}{$\begin{array}{l}\text { Capatazia } \\
(87,4 \%)\end{array}$} & Cais & $\begin{array}{c}66 \\
(75,8) \\
\end{array}$ & Movimentação de cargas. & $\begin{array}{l}\text { Chuva, vento, umidade e } \\
\text { radiação não ionizante. }\end{array}$ & $\begin{array}{l}\text { Fezes de } \\
\text { pombos. }\end{array}$ \\
\hline & $\begin{array}{l}\text { Pátio } \\
\text { automotivo }\end{array}$ & $4(4,5)$ & Movimentação de cargas. & $\begin{array}{l}\text { Chuva, vento, umidade e } \\
\text { radiação não ionizante. }\end{array}$ & $\begin{array}{l}\text { Fezes de } \\
\text { pombos. }\end{array}$ \\
\hline & Oficina & $3(3,4)$ & $\begin{array}{l}\text { Inalação substâncias presente } \\
\text { nas tintas, vernizes e solventes. }\end{array}$ & ---- & --- \\
\hline & $\begin{array}{l}\text { Portão de } \\
\text { entrada }\end{array}$ & $3(3,4)$ & Movimentação de cargas. & $\begin{array}{l}\text { Chuva, vento, umidade e } \\
\text { radiação não ionizante. }\end{array}$ & $\begin{array}{l}\text { Fezes de } \\
\text { pombos. }\end{array}$ \\
\hline \multirow[t]{3}{*}{ Estiva $(9,1 \%)$} & Convés & $3(3,4)$ & Movimentação de cargas. & $\begin{array}{l}\text { Chuva, vento, umidade e } \\
\text { radiação não ionizante. }\end{array}$ & $\begin{array}{l}\text { Fezes de } \\
\text { pombos. }\end{array}$ \\
\hline & Porão & $3(3,4)$ & Movimentação de cargas. & $\begin{array}{l}\text { Chuva, vento, umidade e } \\
\text { radiação não ionizante. }\end{array}$ & $\begin{array}{l}\text { Fezes de } \\
\text { pombos. }\end{array}$ \\
\hline & $\begin{array}{l}\text { Chata ou } \\
\text { avarenga }\end{array}$ & $2(2,2)$ & Movimentação de cargas. & $\begin{array}{l}\text { Chuva, vento, umidade e } \\
\text { radiação não ionizante. }\end{array}$ & $\begin{array}{l}\text { Fezes de } \\
\text { pombos. }\end{array}$ \\
\hline $\begin{array}{l}\text { Conferentes } \\
\text { de cargas } \\
(3,4 \%)\end{array}$ & $\begin{array}{l}\text { Rampa do } \\
\text { navio }\end{array}$ & $3(3,4)$ & Movimentação de cargas. & $\begin{array}{l}\text { Chuva, vento, umidade e } \\
\text { radiação não ionizante. }\end{array}$ & $\begin{array}{l}\text { Fezes de } \\
\text { pombos. }\end{array}$ \\
\hline
\end{tabular}

\section{- DISCUSSÃO}

A partir dos resultados apresentados, observou-se que houve predominância de homens, acima dos 50 anos de idade, e com média de tempo de serviço superior a 15 anos. Nesse viés, sabe-se que o desenvolvimento de doenças relacionadas ao trabalho, muitas vezes não é imediato. Depende dentre outros fatores do tempo em que o trabalhador está exposto a fontes de riscos ambientais, bem como da própria condição orgânica, ou seja, é um processo cumulativo, que se desenvolve e potencializa no decorrer dos anos.

O ambiente de trabalho portuário possui diversas fontes de riscos à saúde ${ }^{(4)}$, o que significa que a maioria dos Trabalhadores Portuários Avulsos (TPA) encontra-se em um ambiente exposto a risco físico, químico e biológico.

Conforme estudo, identificou-se que as condições climáticas afetam e potencializam o Material Particulado exposto no ambiente, sendo que em altas temperaturas, há maior concentração de poluentes. Também existe uma relação entre a concentração de material particulado e a refletividade das nuvens que levam aos efeitos de queda ou diminuição da temperatura. Matérial particulado compreende uma mistura de partículas extremamente pequenas presente no ar que, ao serem inaladas, podem afetar o sistema repiratório e cardiovascular ${ }^{(15-16)}$.

A fonte de exposição de risco químico decorreu tanto da movimentação de cargas, como dos fertilizantes e dos veículos automotores, associado às condições climáticas. Os fertilizantes são substâncias orgânicas e inorgânicas, constituídos por três principais compostos: o Potássio (K), o Fósforo (P) e o Nitrogênio (N)-NPK. Conforme a International Fertilizer Industry Association (IFA) e a United Nations Environment Programme (UNEP) ${ }^{(17)}$, aproximadamente 99\% do suprimento do nitrogênio é produto da amônia (NH4), porém, para sua utilização e aplicação, o suprimento do nitrogênio precisa ser transformado em outras substâncias, como, por exemplo, a ureia (NH3), carga transportada na maior parte das operações portuárias observadas.

Reiterando a interface entre o ambiente e o trabalho no processo saúde-doença, salienta-se a exposição à poeira oriunda do carregamento de cargas como a ureia. Esta, quando armazenada e 
transportada, não oferece riscos à saúde, porém em contato com o sistema respiratório pode causar irritação na garganta, queimaduras e inchaço nas vias aéreas ${ }^{(18)}$. Esta fonte de risco decorre do trabalho de carregamento e descarregamento deste fertilizante.

Observou-se que, durante o carregamento de ureia nos navios, há perda destes no solo, e em dias úmidos ou quentes ocorre sua volatilização, ou seja, a eliminação da amônia no ar. Ao ser eliminada, a substância entra em contato com óxidos de enxofre presentes na atmosfera. Quando em altas concentrações, aumenta a concentração de nitrato, que em contato com o sangue oxida as hemoglobinas, dificultando assim o transporte de oxigênio para os tecidos, interferindo na hematose alveolar ${ }^{(19-20)}$.

No contexto portuário, cabe também ao enfermeiro na especialidade de Enfermagem do trabalho, identificar os fatores de risco ocupacional que podem, direta ou indiretamente, causar agravos à saúde do trabalhador. Na realização do trabalho no cais, observou-se a exposição ao risco químico decorrente da movimentação de fertilizantes, bem como da emissão de gases da queima de combustíveis dos caminhões, máquinas e automóveis que circulam no ambiente.

Dependendo da concentração e do tempo de exposição diária e contínua do trabalhador, o monóxido de carbono pode causar agravos, como conjuntivite, cefaleia e dispneia, bem como, quanto maior tempo exposto, pode causar perda da percepção visual e do tempo ${ }^{(20)}$. Resultado de pesquisa identificou em trabalhadores sintomas como bronquite crônica, enfisema pulmonar e doenças obstrutivas $^{(21)}$. Estudos também evidenciaram que a exposição diária e contínua ao monóxido de carbono e o sulfureto de hidrogênio podem causar Doença Pulmonar Obstrutiva Crônica (DPOC) e até a morte ${ }^{(22)}$.

Outros agravos respiratórios importantes decorre do trabalho de soldagem, realizado por trabalhadores na oficina do cais desta pesquisa, em que há a eliminação do composto aço inoxidável, decorrente da fumo da solda, podendo causar lesão pulmonar aguda ${ }^{(23)}$ e danos crônicos como as pneumoconioses. Estas são compreendidas como um grupo de doenças ocupacionais, cuja ocorrência depende do tamanho das partículas inaladas. Para atingir as vias aéreas inferiores, o material particulado tem que medir menos de $10 \mu \mathrm{m}$, pois o organismo tem mais dificuldade em combater com seus mecanismos de defesa, instalando-se, assim, um processo inflamatório. Podem ser agravadas a partir da exposição pela poluição do ambiente, ao passo que, no decorrer dos anos, pode levar à formação de enfisema ou fibrose e a quadros de limitação crônica ao fluxo aéreo, causando principalmente dispneia ao esforço ${ }^{(24)}$.

Outras substâncias químicas, como o Cloro $(\mathrm{Cl})$ e os gases derivados do nitrogênio e enxofre (presente na atmosfera, devido ao processo químico que ocorre durante a voltatilização da amônia), quando em altas concentrações e em tempo prolongado de exposição do trabalhador, podem provocar alterações no trato respiratório superior ${ }^{(25)}$. Com o passar dos anos, de forma cumulativa, a ureia (NH3) também pode causar alterações nas condições orgânicas do trabalhador, sendo necessário a manutenção e/ou a adaptação ao ambiente para o equilíbrio da estrutura funcional e conservação da saúde(26).

Referente a fonte de risco biológico, observou-se o predomínio de pombos no ambiente externo do porto. Estes animais podem transmitir a Criptococose, que é um agravo respiratório decorrente da inalação da poeira contendo fezes secas dos agentes. Podem causar infecção pulmonar assintomática, atingir o Sistema Nervoso Central (SNC) e se disseminar para outros órgãos ${ }^{(27)}$. Deste modo, os desafios quanto às ações de saúde voltadas à proteção dos trabalhadores, conforme o Institute of Medicine (IOM), decorre dentre outros, de fatores individuais como as crenças e a percepção de riscos; de fatores ambientais, que incluem a disponibilidade de Equipamentos de Proteção Individual (EPI), bem como de fatores organizacionais, como os programas de treinamento. A articulação destes fatores é um dos principais componentes para promoção de segurança nos serviços ${ }^{(28)}$.

Enfatiza-se, então, a realização de ações de saúde voltadas ao trabalhador, no ambiente portuário, reiterando a identificação da exposição a riscos para ações na promoção da saúde e prevenção de agravos decorrente do trabalho( ${ }^{(29)}$.

Devido às características do trabalho portuário, relacionadas à rotatividade dos trabalhadores e sua funções, bem como a não realização das observações no período noturno e nos finais de semana, 
não foi possível um número maior de observações, nem atingir todas as categorias de trabalhadores portuários, apresentando-se como um limite do estudo.

\section{- CONCLUSÃO}

Foram observadas a exposição ambiental e as fontes de riscos presentes no trabalho dos TPA e estes podem provocar alterações funcionais respiratórias de grande significância..O trabalhador portuário está exposto frequentemente às fontes de riscos ocupacionais, que variam conforme suas atividades e locais de trabalho, o que pode torná-lo mais ou menos vulnerável.

Os trabalhadores mais expostos foram os que atuavam na categoria da capatazia, por desenvolverem a maior parte de suas atividades no cais, ambiente que os expõe a diferentes fontes de riscos ocupacionais, como por exemplo, a radiação ionizante, o vento, a umidade, a presença de pombos e formação de poeira de fertilizantes.

O enfermeiro deve realizar intervenções de saúde, de forma a incentivar a utilização de Equipamentos de Proteção Individual afim de evitar ou minimizar a exposição ocupacional, bem como desenvolver ações educativas de promoção da saúde e prevenção de agravos respiratórios. Sendo assim, faz-se necessária uma abordagem socioambiental para melhorar a qualidade de trabalho e a satisfação dos TAP.

\section{AGRADECIMENTOS}

Os autores agradecem o apoio recebeido do CNPq e a Fundação de Amparo à Pesquisa do Estado do Rio Grande do Sul (FAPERGS) sob a forma de financiamento do macroprojeto "Saúde do trabalhador, riscos, acidentes e doenças relacionados ao trabalho: estudo em um porto no extremo sul do Brasil" (Chamada FAPERGS/MS/CNPq/SESRSn.002/2013 Programa pesquisa para o Sistema Único de Saúde (SUS): gestão compartilhada em saúde PPSUS-2013/2015).

\section{REFERÊNCIAS}

1. Rondon EM, da Silva RMVG, Botelho C. Sintomas respiratórios como indicadores de saúde em trabalhadores de indústrias de cerâmica. J Bras Pneumol. [Internet] 2011;37(1) [acesso em 31 mar 2017]. Disponível: http://www. jornaldepneumologia.com.br/detalhe_artigo.asp?id=1109.

2. Dapper SN, Spohr C, Zanini RR. Poluição do ar como fator de risco para a saúde: uma revisão sistemática no estado de São Paulo. Estud. av. [Internet] 2016;30(86) [acesso em 31 mar 2017] Disponível: http://dx.doi. org/10.1590/S0103-40142016.00100006.

3. Agência Nacional de Transporte Aquaviário (ANTAQ). Anuário Estatístico Aquaviário. [Internet] 2017 [acesso em 9 fev 2017]. Disponível: http://www.antaq.gov.br/Portal/default.asp.

4. Superintendencia do Porto do Rio Grande (RS). [Internet] 2017 [acesso em 10 fev 2017]. Disponível: http:// www.portoriogrande.com.br/.

5. Cezar-Vaz MR, Soares JFS, de Almeida MCV, Cardoso LS, Bonow CA. Doenças relacionadas ao trabalho autorreferidas por trabalhadores portuários avulsos. Ciênc Cuid Saúde. [Internet] 2010;9(4) [acesso em 10 fev 2017]. Disponível: http://dx.doi.org/10.4025/cienccuidsaude.v9i4.11928.

6. de Almeida MCV, Cezar-Vaz MR, Soares KF, Silva MR. Scientific evidence of dockworker illness to nursing clinical reasoning. Rev. Latino-Am. Enfermagem. [Internet] 2016;50(2) [acesso em 10 fev 2017]. Disponível: http:// www.scielo.br/pdf/reeusp/v50n2/0080-6234-reeusp-50-02-0346.pdf.

7. Sakwari G, Bråtveit M, Mamuya SH, Moen BE. Dust exposure and chronic respiratory symptoms among coffee curing workers in Kilimanjaro: a cross sectional study. BMC Pulm Med. [Internet] 2011;(11) [acesso em 9 fev 2017]. Disponível: http://dx.doi.org/10.1186/1471-2466-11-54. 
8. Zeleke ZK, Moen BE, Bråtveit M. Lung function reduction and chronic respiratory symptoms among workers in the cement industry: a follow up study. BMC Pulm Med. [Internet] 2011;(11) [acesso em 9 fev 2017]. Disponível: http://dx.doi.org/10.1186/1471-2466-11-50.

9. Ministério do Trabalho e Emprego (BR). Norma Regulamentadora $n^{\circ} 29$. Segurança e Saúde no Trabalho Portuário. Brasília: MTE; 1998.

10. Arbex MA, Santos UP, Martins LC, Saldiva PHN, Pereira LAA, Braga ALF. A poluição do ar e o sistema respiratório. J. bras. pneumol. [Internet] 2012;38(5) [acesso em 10 fev 2017]. Disponível: http://dx.doi.org/10.1590/ S1806-37132012000500015.

11. Künzli N, Perez L, Rapp R. Air quality and health. Lausanne: European Respiratory Society; 2010.

12. Usiquímica do Brasil LTDA. Ficha de Informação e Segurança de Produto Químico. Uréia Técnica. FISPQ Revisão: 02 - Data 10/12/2009. [Internet] 2009 [acesso em 10 fev 2017]. Disponível: http://www.usiquimica.com.br/ adm_img/fispq-24.pdf.

13. Ministério do Trabalho e Emprego (BR). Norma Regulamentadora $n^{\circ} 15$. Atividades e operações insalubres. Brasília, DF: MTE; 1978.

14. Ministério da Saúde (BR). Conselho Nacional de Saúde. Diretrizes e Normas Regulamentadoras de pesquisas envolvendo seres humanos. Brasília. Resolução nº 466, de 12 de dezembro de 2012. Brasília; 2012.

15. European Protection Agency (EPA). Particulate Matter. [Internet] 2013 [acesso em 17 fev 2017]. Disponível: https://www.epa.gov/pm-pollution.

16. Nie W, Wang T, Wang W, Wei X, Liu Q. Atmospheric concentrations of particulate sulfate and nitrate in Hong Kong during 1995 e 2008: Impact of local emission and super regional transport. Atmospheric Environment. [Internet] 2013;(76) [acesso em 17 fev 2017]. Disponível: https://doi.org/10.1016/j.atmosenv.2012.07.001.

17. International Fertilizer Industry Association (IFA). United Nations Environment Programme (UNEP). O uso de fertilizantes minerais e o meio ambiente. [Internet] Trad. Associação Nacional para Difusão de Adubos (ANDA); 2000. [acesso em 10 fev 2017]. Disponível: http://www.anda.org.br/multimidia/fertilizantes_meio_ambiente.pdf.

18. Health Protection Agency (HPA). Compendium of Chemical Hazards Ammonia. United Kingdom. [Internet] 2016 [acesso em 30 mar 2017]. Disponível: https://www.gov.uk/government/uploads/system/uploads/attachment_ data/file/561050/ammonia_general_information.pdf.

19. United States Department of Labor. Occupational Safety and Health Administration (OSHA). Diesel Exhaust/ Diesel Material particulado. [Internet] 2013 [acesso em 10 fev 2017] Disponível: https://www.osha.gov/dts/ hazardalerts/diesel_exhaust_hazard_alert.html.

20. Fonseca FR, Vasconcelos CH. Distribuição de doenças respiratórias. Cad. Saúde Colet. [Internet] 2011;19(4) [acesso em 10 fev 2017]. Disponível: http://saudepublica.bvs.br/pesquisa/resource/pt/lil-641468.

21. Bagatin E, Costa EA. Sociedade Brasileira de Pneumologia e Tisiologia. Doenças das vias aéreas superiores. J Bras Pneumol. [Internet] 2006;32(Suppl 1) [acesso em 9 fev 2017]. Disponível: http://www.scielo.br/pdf/jbpneu/ v32s2/a04v32s2.pdf.

22. Ezejiofor TIN, Ezejiofor AN, Orisakwe OE, Nwigwe HC, Osuala FO, Iwuala MOE. Anicteric hepatoxicity: a potential health risk of occupational exposures in Nigerian petroleum oil refinin and distribution industry. J Occup Med Toxicol. [Internet] 2014;9(1) [acesso em 10 fev 2017]. Disponível: http://dx.doi.org/10.1186/1745-66739-3.

23. Bonow CA, Cezar-Vaz MR, da Silva LRW, Rocha LP, Turik C. Health disorders related to learning the welding trade: assessment of approaches to risk communication. Rev. Latino-Am. Enfermagem. [Internet] 2014;22(1) [acesso em 9 fev 2017]. Disponível: http://dx.doi.org/10.1590/0104-1169.3094.2384.

24. Conselho Nacional do Meio Ambiente (CONAMA). Resolução n. 3, de 28 de junho de 1990. Dispõe sobre padrões de qualidade do ar, previstos no PRONAR. Brasília, DF: Diário Oficial da União, 2 abr. 1990. p. 6408.

25. Lopes AC. Tratado de clínica médica. São Paulo: Rocca; 2006. 
26. Yara. Yara's various production processes. Nitrogen. [Internet] 2017 [acesso em 10 fev 2017]. Disponível: http:// yara.com/about/production_sites/production_process_story/production_processes/.

27. Miranda C, Ladendorff N, Köbl T. Percepção da população sobre a participação dos pombos (columba livia domestica) na transmissão de zoonoses. Asa. [Internet] 2014;2(1) [acesso em 9 fev 2017]. Disponível: http://www. revistaseletronicas.fmu.br/index.php/ASA/article/view/362.

28. Institute of Medicine. Preparing for an Influenza Pandemic: Personal Protective Equipment for Healthcare Workers. [Internet] Washington, DC: The National Academies Press; 2008 [acesso em 9 fev 2017]. Disponível: https://www.nap.edu/read/11980/chapter/1\#iii.

29. Soares JFS; Cezar-Vaz MR; Sant'anna CF. Prevenção de agravos e promoção da saúde: um estudo com trabalhadores portuários. Texto Contexto Enferm. [Internet] 2011;20(3) [acesso em 10 fev 2017]. Disponível: http:// dx.doi.org/10.1590/S0104-07072011000300002. 